Allen, being very highly cited. One explanation for high citation rates for people near the start of the alphabet may be childhood conditioning. Children with names near the start of the alphabet are frequently called on by teachers to do things first and consequently not only get more attention but also more criticism when they fail (as they will be the first in the class to be seen to fail). Consequently, these people may either get used to failing in public or expect to do things first and well. Some of these children will therefore grow up with a heightened desire to achieve.

Less recent correspondence in Nature proposed that success rate in examinations, and in sport, depended on birth date being near the start of the school or sporting year. One might therefore predict that the children most likely to do well are those born early in the school year to families with surnames near the beginning of the alphabet.

In conclusion, it would be unfair to penalize over-achievers at the start of the alphabet by the modifying factor suggested by Tregenza. But then we would say that, wouldn't we?

Jan Alexander

Julian Andrews

School of Environmental Sciences,

University of East Anglia,

Norwich NR4 7TJ, UK

\section{No knife needed}

Sir-I was disappointed to read that you feel that, as South Africa seeks to reform its science base, it would be a mistake if the research of the Atomic Energy Corporation (AEC) were to escape the knife (Nature 384, $1 ; 1996)$.

In 1990 the corporation put in place, of its own volition, a ten-year plan to reduce its dependence to the level sufficient only to fund the national requirements of the state.

In the sixth year of the plan, state dependence has been reduced by $72 \%$. This has been achieved by closing down research programmes not deemed relevant to the new South Africa and by commercializing many of the unique technologies developed during the period of political isolation.

Not that these cutbacks have been without loss: it is estimated that South Africa lost 22,000 man-years of high-level scientific experience in the process. On the other hand, the commercialized technologies are now being manufactured (without state subsidy) and marketed both locally and overseas. Sales in the present financial year (excluding traditional nuclear fuels) will be R148 million, of which 35\% will be to international markets.

During this transition, the corporation has made some major achievements. In
1989-90, for example, the AEC dismantled the South African nuclear deterrent, and this was subsequently verified and favourably commented on by the International Atomic Energy Agency. More than a million patients benefit annually from radio pharmaceuticals, mainly molybdenum-99 for nuclear medicine, prepared in the corporation's laboratories. The markets are Australia, China, India, the European Union, Israel and sub-Saharan Africa. The corporation is leading research towards the single step enrichment of uranium by molecular laser isotope separation techniques. In addition, both the US and Russian space agencies are evaluating precooked foods irradiated by the AEC for long shelf-life.

The AEC has emerged from this continuing transformation with a reputation in South Africa as an applied research organization with a proven competence to deliver technologies to the market. Our recent annual report shows that the knife is now neither necessary nor deserved. The AEC has for many years now had an open door policy, and we welcome visitors. Our website address is: http:॥www.aec.co.za.

\section{D. Hyslop}

Atomic Energy Corporation of South Africa

Limited, $P O$ Box 582 ,

Pretoria 0001, South Africa

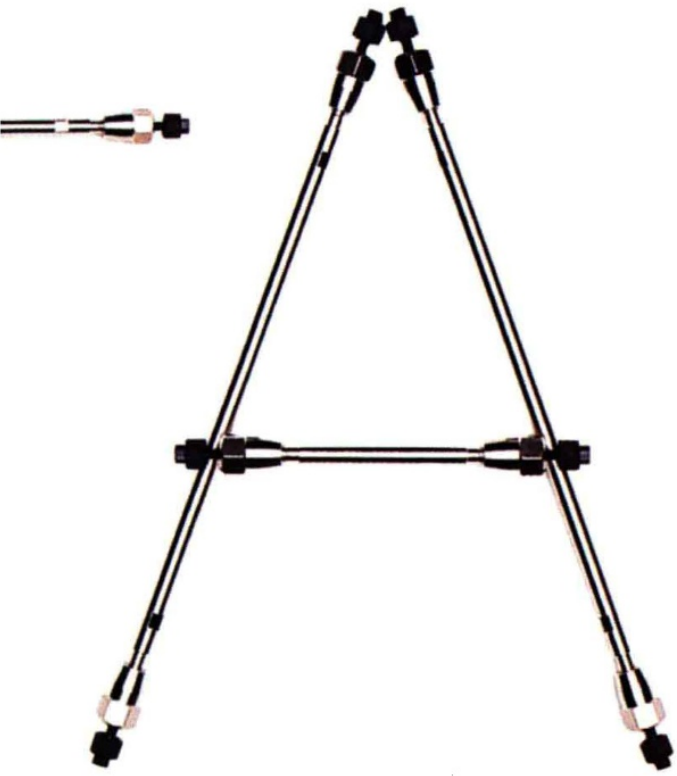

Are you working with natural peptides? Synthetic peptides? Recombinant peptides? Peptide fragments? Or all of them? Whatever peptide you work with, your options for purifying them just increased.

With ten new columns for reversed phase chromatography, you're nearly certain of finding the selectivity you need in our extensive range. All of these new RPC columns deliver high resolution; combined, they'll take you from purification and analysis to peptide mapping.

We can support you with advice and solutions for other peptide purification techniques as well. Are you separating peptides with poor solubility? Our new size exclusion column withstands high $\mathrm{pH}$ and solvents. Do you need an extra technique to help you with a difficult-to-separate pept.ide? We have two new ion exchange columns that permit very high resolution and withstand high $\mathrm{pH}$ ranges.

What's more, all 13 columns are supported by ÄKTA ${ }^{\text {TM }}$ purifier-a revolutionary new purification system for peptides, oligonucteotides and other biomolecules. Its preset protocols let you resolve all major purification tasks quickly and easily. Its control system lets you instantly transfer your methods to purification systems at all scales.

Want to know more about our peptide purification solutions? Call us: I (800) 5263593 from the USA; +8I (0)3 34926949 from Japan; or $+46(0) 181650$ । I from Europe and the rest of the world; or meet us on the Internet at http://www.biotech.pharmacia.se.

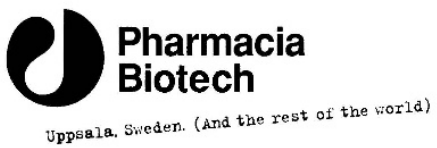

